
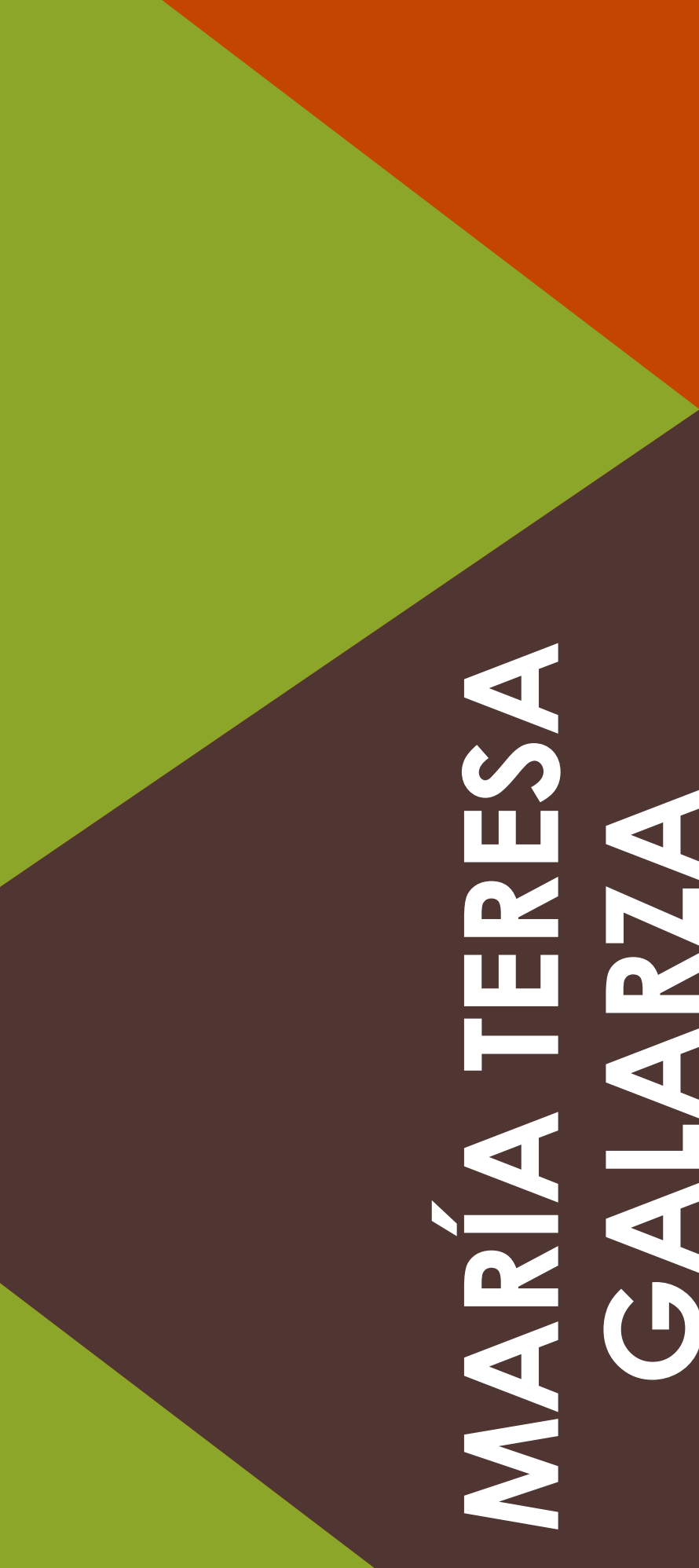


\title{
Arpilleras de Wellington: los hilos de la memoria, un allá cercano y un pasado contemporáneo
}

\section{Wellington Arpilleras: the threads of memory, a near-by far away, and a contemporary past}

\section{María Teresa Galarza}

ISSN (imp): 1390-4825

ISSN (e): 2477-9199

\author{
Fecha de recepción: 14/04/18 \\ Fecha de aceptación: 13/05/18
}

\section{Resumen:}

Este texto plantea una reflexión política en torno a la práctica creativa de las Arpilleras de Wellington, un colectivo de mujeres arpilleristas, migrantes latinoamericanas en Aotearoa Nueva Zelanda. Frente a la práctica de las arpilleristas de Wellington, se propone una lectura acerca del carácter ético y político de sus intervenciones en ámbitos y espacios relacionados con el arte, la academia y la comunidad. Esta lectura se articula desde la perspectiva de una particular noción de "contemporaneidad", afincada en las preguntas de Giorgio Agamben "¿De quién y de qué cosa somos contemporáneos? Y, sobre todo, ¿qué significa ser contemporáneo?”

\section{Palabras clave:}

Arpilleras, colectivos de mujeres, arte político contemporáneo

\section{Abstract:}

This text is a political reflection about the creative practice of the Wellington Arpilleras, a collective of Latin American women, living in Aotearoa New Zealand. This inquiry about the Wellington Arpilleras offers a way of "reading" their practice, by bringing forward the ethical and political nature of those group's interventions that pass-through spaces often reserved to art, academia, and community. To articulate this paper, it is necessary to recall the notion of contemporaneity in Giorgio Agamben. Therefore, Agamben's questions "'Of whom and of what are we con-temporaries?' and, first and foremost, 'What does it mean to be contemporary?"” are the starting point this inquiry into Wellington Arpilleras practice, with an ethicalpolitical perspective.

\section{Key Words:}

Arpilleras, women collectives, politic contemporary art

\section{Biografía de la autora:}

María Teresa Galarza. Cuenca, 1981. Practicante del arte e investigadora de temas de género, arte, cultura y Derechos Humanos. Tiene licenciaturas en Cine y Educación, Leyes; tiene una maestría en Estudios de la Cultura por la UASB y cursó estudios doctorales en Literatura Latinoamericana en la misma institución. Es Ph.D. por el Victorian College of the Arts de la Universidad de Melbourne. Ha trabajado, asesorado y sido consultora en temas de comunicación, arte y educación artística para instituciones públicas y privadas. Actualmente es docente de la Facultad de Artes de la Universidad Central del Ecuador. 
El colectivo se autodefine como "un grupo de (en su mayoría) mujeres latinoamericanas trabajando con arpilleras para explorar los sentidos y sentimientos de estar aquí en Aotearoa Nueva Zelanda, teniendo raíces en otros lados ${ }^{1}$." Respecto de las indagaciones interpersonales que tienen lugar durante sus encuentros de creación colectiva, las creadoras anotan: "aquí reflexionamos acerca de nuestras experiencias como migrantes en Aotearoa Nueva Zelanda, en particular en términos de memorias, identidad y construcción de comunidad ${ }^{2}$ ".

A partir de entonces, y través del establecimiento de un espacio seguro y comunitario, marcado por la construcción de lazos de confianza y solidaridad, estas mujeres, que residen en Aotearoa Nueva Zelanda "teniendo raíces en otros lados," se convirtieron paulatinamente en arpilleristas. Las arpilleristas de Wellington nos proponen una definición propia, un modo de entender su práctica y a sí mismas, como practicantes:

Arpilleras son objetos simples y poderosos. En ellos se engarzan las realidades afectivas, íntimas y políticas de los arpilleristas (las hacedoras).

Las arpilleras son tapices cosidos a mano hechos de retazos de tela. Hablan visualmente, transmiten procesos de memoria y la búsqueda de justicia. Primero fueron hechas en Chile por parientas de víctimas de la dictadura en la década de 1970, y desde entonces han sido producidas en diferentes partes del mundo ${ }^{3}$.

En cierto sentido, esta definición, que da cuenta de los orígenes histórico-geográficos y de los fines u objetivos de la creación de arpilleras, sugiere también una declaración del horizonte ético y político de la práctica en sí misma, y, tal vez, una declaración de intenciones de "las hacedoras". Esta definición marca el carácter eminentemente femenino de una práctica de creación textil que, re-significada en

1 https://www.arpilleraswellington.com/ (fecha de consulta: 30 de marzo de 2018)

2 https://www.arpilleraswellington.com/our-story. html (fecha de consulta: 30 de marzo de 2018)

3 https://www.arpilleraswellington.com/about-arpilleras.html (fecha de consulta: 30 de marzo de 2018) La traducción es mía. respuesta a los imperativos de un contexto político inevitable, se (re)carga de intencionalidad política, y se constituye en una estrategia de documentación, una suerte de repositorio táctil y visual de la memoria, capaz de desafiar y "expandir definiciones tradicionales de registro.” (Doolan 2016)

Esta es re-significación de la creación textil, colectiva y de unas mujeres que, en lo (tradicionalmente considerado) intimo del tejido y la costura, consigna lo (tradicionalmente considerado) público de una experiencia histórica y comunitaria compartida. Así, la práctica se convierte en un ejercicio de documentación-creativa, que revela dimensiones extraordinarias y posibilidades subversivas de la tradicional relación entre la mujer y el arte textil.

En el modo de entender y explicar sus obras y a sí mismas, propuesto por las Arpilleras de Wellington, se establece un elemento fundamental de la práctica actual: la producción contemporánea de arpilleras se ha trasladado hoy desde el Chile de la dictadura de Pinochet hacia otras partes del mundo, probablemente coincidiendo con la configuración de comunidades chilenas asentadas en otras tierras, como resultado de esos procesos de migración y exilio, acentuados durante el período dictatorial.

Pero la arpillera, además de constituirse en un ejercicio de documentación y registro de la memoria que hoy se produce en diversas partes del mundo, también ha encontrado su espacio en museos, galerías y bienales de arte. La arpillera, que guarda muchas semejanzas con otras formas de arte textil como el tejido, ha tenido que disputar, junto con ellas, un espacio en el mundo del arte, desmantelando dicotomías sobre lo artesanal y lo artístico, y reivindicando el reconocimiento que corresponde a ciertas formas contemporáneas y subversivas de prácticas tradicionalmente atribuidas a las mujeres. En esta línea, la artista textil Teresa Lanceta explica, desde su propia experiencia e intereses, como percibió esta trayectoria hacia el reconocimiento de una práctica artística, en general, de mujeres, confinada durante mucho tiempo los límites de una noción hegemónica de "arte":

De manera resumida, por lo tanto bastante estereotipada, lo que me interesa es el arte, sus límites y limitaciones, en el sentido de "otro arte" y el "arte de los otros". Actualmente la cuestión de la alteridad está integrada en nuestro discurso, aunque todavía 
hay mucho que recorrer, pero cuando empecé estaban denostados los tejidos, las mujeres tejedoras, las artesanías.

La práctica creativa de las arpilleras puede ser leída como un modo de documentación con un valor testimonial innegable, o ser interpretada desde la perspectiva de la creación textil y su propia trayectoria para posicionarse y reivindicar su valía en el campo del "arte", y se posicionan en el extenso campo del arte textil; además, las arpilleras contemporáneas empiezan a transitar otros espacios y a construirse nuevos literarios.

Por ejemplo, el colectivo de Arpilleras de Wellington se ha caracterizado por poner su práctica en discusión constante, en diversos eventos e instituciones relacionados con el arte, la academia y la comunidad. Por ejemplo, el colectivo presentó una mesa de trabajo-taller, en el marco de la conferencia 2016 de la Asociación de Estudios Ibéricos y de Latinoamérica AILASA. En la mesa, varias representantes del grupo dieron cuenta de sus experiencias de creación individual y compartida durante sus años de colaboración, y presentaron, en ese escenario académico, una muestra de arpilleras creadas por el colectivo. En ese punto, se propuso una lectura de las arpilleras en el contexto de las metodologías visuales de investigación. Las arpilleras fueron explicadas en AILASA también como estrategias de configuración "identitaria," y tácticas para la (re)construcción de la memoria, que por su materialidad, han dado lugar a la creación de un archivo de recuerdos, esperanzas y afectos con presencia concreta. Cabe anotar que a esa mesa de trabajo asistieron como facilitadoras arpilleristas de Wellington vinculadas y no vinculadas con la academia y, en algunos casos, fueron acompañadas por sus pequeños hijos. El taller de creación colectiva que siguió a la presentación inicial dio a los y las participantes (algunas de nosotras, también con nuestras hijas pequeñas), la oportunidad de experimentar con materiales, formas y colores en un proceso de creación colectiva de una arpillera que nació en el evento.

Más allá del ámbito académico, de los museos por los que han transitado, de las discusiones formales y metodológicas, las creaciones de las Arpilleras de Wellington se bordan desde la subjetividad de mujeres latinoamericanas migrantes en Aotearoa Nueva Zelanda y, frecuentemente, en sus variados escenarios de creación colectiva, las acompañan, colaboran y participan sus hijos e hijas. Por excepción, por las características de la práctica y el colectivo mismos, en AILASA 2016 "la academia" tuvo la oportunidad de experimentar una inusual presencia infantil en un evento de esta naturaleza.

Si leemos a las arpilleras desde la perspectiva de las reflexiones de Jacques Rancière acerca de "las paradojas del arte político," la creación e intervenciones de las Arpilleras de Wellington podrían ser entendidas como "práctica[s] que sacude[n] la distribución de lugares y competencias, y que de ahí en adelante trabaja[n] para difuminar los bordes que definen [la] propia actividad" (Rancière 2010, p. 149). Siguiendo esta la línea de reflexión podríamos decir que ese sacudón de "lugares y distribución de competencias" pone en jaque la "partición de lo sensible" que él entiende como una división del mundo y la gente, que adjudica espacios a los sujetos, separando y excluyendo con el objetivo de permitir una "participación" de los sujetos, circunscrita siempre a esos espacios que les corresponden. (Rancière 2010, p. 36).

Las Arpilleras de Wellington transitan fluidamente por territorios usualmente adjudicados a lo doméstico, a lo académico, a lo artístico, reflexionando con y a través de la aguja y el hilo acerca de su identidad y memoria, y afincando esa reflexión tanto en sus orígenes latinoamericanos como en los orígenes de la práctica en sí, en el Chile de la dictadura.

El poderoso anclaje del colectivo con la comunidad (por tanto, con la historia) chilena hace que los orígenes de resistencia social y política de las arpilleras chilenas, y el contexto en el que se produjeron, femenino y comunitario, se reactualicen de cierta manera en esas prácticas de costura, bordado y tejido de una memoria colectiva atravesada por los afectos, que llevan adelante las arpilleristas de Wellington.

Desde sus inicios, las arpilleristas chilenas hicieron un ejercicio subversivo de documentación y resistencia y a través de prácticas tradicionalmente femeninas, construyeron un registro palpable de los efectos de la violencia y el horror en sus respectivas comunidades, bordando una suerte de archivo que, subestimado por las estructuras de poder de la época, fue capaz de fijar sobre la tela la memoria del escenario sociopolítico de su momento histórico y pervivir para mostrarse. En cierto sentido, como explica Susan Traini, las arpilleras chilenas han evitado "el olvido de lo inolvidable" (Traini, 
2013). Las arpilleristas de Wellington, inspiradas por la presencia de estos poderosos testimonios de la historia chilena, retomaron esta práctica para, a partir de ella, interpelar a sus propias identidades. Este ejercicio de reapropiación mantiene nexos con el movimiento creativo inicial enraizado en Chile, pues es también un proceso de construcción individual y comunitaria a través de talleres de trabajo en los que las mujeres se juntan en un espacio seguro que permite articular discursos desde un yo colectivo y, al mismo tiempo, desarrollar relaciones intersubjetivas y crear desde una afectividad compartida.

Volvemos entonces a las preguntas de Agamben, "¿de quién y de qué cosa somos contemporáneos? Y, sobre todo, ¿qué significa ser contemporáneo?" (Agamben 2009, p. 39). Para Agamben, ser contemporáneo implica "ser puntuales en una cita a la que se puede solo faltar" (Agamben 2009, p. 46); "la contemporaneidad," a su entender, significa ser capaces de alejar la mirada de las luces y fijarla en las tinieblas del tiempo presente, encontrando en ellas los rastros de un pasado que nunca ha dejado de ser del todo. Agamben nos recuerda que arcaico quiere decir "cercano al origen" (arké) y que este origen no puede entenderse sólo como un evento ubicado en un pasado temporal, sino como un elemento "contemporáneo del devenir histórico que no cesa de operar en él, como el embrión continúa actuando en los tejidos del organismo maduro" (Agamben 2009, p. 50). En este sentido, la forma originaria de una práctica creativa localizada en un lugar y un tiempo determinados puede ser "contemporánea de sus formas posteriores," en tanto que sigue operando en ellas como elemento sustancial y constitutivo, aún cuando haya una distancia cronológica considerable entre ambas. Así, la práctica individual y colectiva que ocurre entre las arpilleristas de Wellington puede ser "contemporánea "de los procesos de creación originales de arpilleras en Chile, en la medida en que estos están inscritos en el origen y modos de hacer de aquellas.

A través de sus procesos creativos, las Arpilleras de Wellington han establecido puentes no solo entre dos tiempos, pasado y presente, sino entre dos continentes separados por un océano. $\mathrm{Si}$ "las tinieblas del presente" a las que se refiere Agamben pudieran ser entendidas también como esos vacíos en la memoria histórica y comunitaria que inevitablemente se forjan frente a situaciones de trauma, desplazamiento y reasentamiento, la práctica de las Arpilleras de Wellington va fijando la mirada en esas oscuridades para in- terpelarse e interpelarlas, en un proceso de creación comunitaria que involucra varias generaciones.

El contemporáneo no es solamente aquel que, percibiendo la oscuridad del presente aferra la inamovible luz; es también aquel que, dividiendo e interpolando el tiempo, está en grado de transformarlo y de ponerlo en relación con los otros tiempos, de leer de modo inédito la historia, de "citarla" según una necesidad que no proviene en algún modo de su arbitrio, sino de una exigencia a la cual no puede no responder. (Agamben 2009, p. 53)

\section{BIBLIOGRAFÍA}

Agamben, G. (2009). "What Is the Contemporary?" En What is an apparatus? and other essays, (pp. 39-54). Stanford, Stanford University Press.

Bacic, R. (2008). Arpilleras que claman, cantan, denuncian e interpelan. Hechos del Callejón (Programa de Naciones Unidas para el Desarrollo, PNUD) (42) 20-22.

Doolan, E. (2016). Textiles of Change: How Arpilleras can Expand Traditional Definitions of Records. InterActions: UCLA Journal of Education and Information Studies 1 (12, pp. 9).

Rancière, J. (2010). Dissensus: On Politics and Aesthetics. London, New York: Continuum.

Traini, S. (2013). Unforgotten to the unforgettable: How Arpilleras contributed to Chilean history informing everyday occupations and social change. Journal Of Prevention Assessment \& Rehabilitation, 93-96. Recuperado de https://www.arpilleraswellington.com/ 